\title{
Standardize Hasta Kullanılarak Yapılan Bir Ruh Sağlığı ve Psikiyatri Hemşireliği Klinik Simülasyon Deneyimi
}

\author{
Gizem Şahin ${ }^{1} \odot$, Oya Sağır Koptaş²๑, Sevim Buzlu ${ }^{1}$
}

'İstanbul Üniversitesi - Cerrahpaşa, Florence Nightingale Hemşirelik Fakültesi, Ruh Sağlığı ve Psikiyatri Hemşireliği Anabilim Dalı, İstanbul, Türkiye

${ }^{2}$ Acıbadem Üniversitesi, CASE, İstanbul, Türkiye

Gizem Şahin, Arş. Gör. Oya Sağır Koptaş, Uzm. Hemş. Sevim Buzlu, Prof. Dr.

Illetişim:

Arş. Gör. Gizem Şahin

İstanbul Üniversitesi - Cerrahpaşa, Florence Nightingale Hemşirelik Fakültesi, Ruh Sağlığı ve Psikiyatri Hemşireliği Anabilim Dalı, İstanbul, Türkiye

Tel: +902122242618

E-Posta: agizemsahin@gmail.com

Gönderilme Tarihi : 20 Haziran 2017

Revizyon Tarihi : 030 cak 2018

Kabul Tarihi : 040 cak 2018

\section{ÖZET}

Amaç: Bu çalışmanın amacı; standardize hasta yöntemi kullanılarak gerçekleştirilen klinik simülasyonun, hemşirelik öğrencilerinin ruhsal bozukluğu olan bireyin ruhsal durumunu değerlendirmelerine yönelik etkinliğini belirlemektir.

Gereç ve Yöntem: Klinik simülasyon öncesi, öğrencilerin klinik uygulama esnasında karşılaşma olanağının en yüksek olduğu ruhsal bozukluklardan olan; şizofreni, majör depresyon ve bipolar bozukluk (manik evre) olmak üzere üç olgunun yer aldığı 10'ar dakikalık senaryo içerikleri hazıılandı. Standardize hasta olarak belirlenen üç profesyonel oyuncuyla yapılan provaların içeriğini; simülasyonun öğrenim hedeflerinin ve içeriğinin aktarılması, olgular için hazırlanan senaryo metinlerinin birlikte okunarak düzenlemelerin yapılması, oyuncunun senaryodaki rolünü canlandırması ve değerlendirme oluşturdu. Klinik simülasyon, üçünci sınıfta eğitim alan 50 Hemşirelik öğrencisi ile gerçekleştirildi. Kayıt altına alınarak gerçekleştirilen simülasyon için katılımcılardan yazılı onam alındı. Klinik simülasyon esnasında standardize hasta ile yapılan görüşmelerde katılımcılar, kolaylaştıııılar (eğiticiler) tarafından hazırlanan "Ruhsal Durum Değerlendirme Formu" nu kullanarak ruhsal bozukluğu olan bireyin ruhsal durumunu değerlendirdi. 'Katııımı Değerlendirme Formu" ise kolaylaştıııılar tarafından simülasyon esnasında öğrencilerin becerilerini değerlendirmek amacıyla kullanıldı. Çözümleme aşamasının sonunda katılımcılara kolaylaştıııılar tarafından hazırlanan "Klinik Simülasyon Memnuniyet Anketi" uygulandı.

Bulgular: Klinik simülasyon uygulamaları sonrası her istasyonun kolaylaştııııısı tarafından PEARLS (Promoting Excellence and Reflective Learning in Simulation) çerçevesi kullanılarak yapılan çözümlemede; ögrencilerin bildirimleri sonucunda, standardize hasta rolünde profesyonel oyuncunun yer almasının yüksek gerçeklik sağlamada ve ruh sağlığı ve psikiyatri hemşireliği klinik simülasyonunun öğrenim hedeflerine ulaşmada etkili olduğu belirlendi.

Sonuç: Klinik simülasyon deneyiminin öğrencilerin klinik uygulama öncesi anksiyetelerini azaltmada ve özgüvenlerini geliştirmede kullanılabilir bir yöntem olduğunun saptanması doğrultusunda, ruh sağlığı ve psikiyatri hemşireliği eğitiminde klinik simülasyonun müfredata entegre edilerek basit ve karmaşık senaryoların yer aldığı klinik simülasyonların planlanması önerilmektedir.

Anahtar sözcükler: Psikiyatri hemşireliği, klinik simülasyon, standardize hasta

\section{A CLINICAL SIMULATION EXPERIENCE ON MENTAL HEALTH AND PSYCHIATRIC NURSING STUDENTS BY USING STANDARDIZED} PATIENTS

\section{ABSTRACT}

Purpose: A clinical simulation was done by using standardized patients in order to ensure that mental health and psychiatric nursing students can assess the mental status examination of patients with mental disorders.

Method: Prior to the simulation, 10-minutes scenarios, which involve the three mental-disorders with the highest probability of encounter in clinical practice, were prepared. The content of the rehearsals done with three professional actors, who acted as standardized patients, was composed of transferring the learning outcomes and the content of the simulation, making adjustments in the scenario text through proofreading, actors' role- playing according to the scenario and evaluation. A clinical simulation was done with 50 third-year nursing students. The simulation was video recorded, and written consents of the participants were obtained.

Results: After implementing the scenarios, the facilitator of each station applied PEARLS (Promoting Excellence and Reflective Learning in Simulation) approach, and, according to the students' statements, it was found that the existence of professional actors in the role of patients has an important influence both on obtaining higher reliability, and on reaching clinical learning outcomes.

Conclusion: In conclusion, it was determined that the simulation was a beneficial method for decreasing students' anxiety before clinical implementations and increasing their self-confidence. In the light of these results, it was recommended that simple and complex versions of simulation implementation should be integrated into the curriculum of mental health and psychiatric nursing.

Keywords: Psychiatric nursing, clinical simulation, standardized patients 


\section{Ruh sağlığı ve psikiyatri hemşireliği eğitiminde klinik simülasyonun önemi}

Ruh sağlığı ve psikiyatri hemşireliği; bilgiyi, deneyimi, hemşirelik becerisini, biyolojik ve sosyal bilim verilerini, kendini terapötik kullanma sanatını birleştiren bir disiplindir (1).

Ruh sağlığı ve psikiyatri hemşireliği eğitimi; ruh sağlığı ve psikiyatri hemşireliğinin temel ilke, kavram, işlev ve sürecini inceleyerek bunları ülke gereksinimleri doğrultusunda ruh sağlığını koruma, geliştirme ve sürdürmede ve ruh sağlığının bozulduğu durumlarda bakım, tedavi ve rehabilitasyonda etkin biçimde kullanımını sağlamayı amaçlar.

Ruh sağlığı ve psikiyatri hemşireliği eğitiminin klinik uygulamasında öğrencilerden psikiyatrik değerlendirme ve görüşme, ruhsal bozukluğu olan bireye bakım verme, terapötik iletişim ve kişilerarası ilişkiler, terapötik hemşirelik girişimleri ve kendi duygu ve düşüncelerinin farkında olma gibi yeterlilikler beklenmektedir. Öğrenciler, klinik uygulama esnasında beklenen yeterlilikleri kazanırken birçok klinik stresör algıladıkları da belirtilmektedir (2). Alzayyat ve arkadaşlarının (2015) yaptığı literatür derlemesinde öğrenciler uygulama esnasında; hasta bakımı, klinik uygulamadaki ilişkiler ve akademik beklentilerin en sık karşılaştıkları stresörler olduğunu ifade etmişlerdir (3). Ruhsal bozukluklara karşı stigmatizasyon ve birçok öğrencinin daha önce ruhsal bozukluğu olan ve/veya intihar/agresyon riski taşıyan bireye bakım vermediği de göz önünde bulundurulduğunda, öğrencilerin yaşadığı orta ve ciddi düzeyde anksiyete; öğrencilerin düşünce süreçlerini, buna bağlı olarak terapötik ilişki kurma becerilerini ve kendinin terapötik kullanımını engelleyebilmektedir (4). Bu nedenle öğrenciler, klinik uygulamaya başlamadan önce özgüven eksikliği ve stres faktörleri nedeniyle risk altındadır (5).

Hemşirelik eğitiminde klinik simülasyon; sanal ortamda, simülatör ve standardize hasta kullanılarak gerçekleştirilmektedir. Simülasyonun hemşirelik eğitiminde kullanımı, öğrencilere klinik uygulama öncesi güvenli ve kontrollü bir ortamda uygulama yapma ve klinik becerilerini geliştirme olanağı sağlar ve anksiyetelerini azaltır $(6,7)$.

Ruh sağlığı ve psikiyatri hemşireliğinde simülasyon; terapötik iletişim becerilerini, eleştirel düşünmeyi, karar vermeyi, sorun çözmeyi ve hata yükümlülüğü ve/veya hastanın zarar verme riski olmadan klinik karar vermeyi öğreten kullanışlı bir yöntemdir (8). Bu nedenle; ruh sağlığı ve psikiyatri hemşireliğinde yer alan ve klinik uygulama yeterliliklerini kapsayan becerilerin geliştirilebilmesi için gereksinime uygun klinik simülasyonlar müfredata entegre edilmektedir (9).

\section{Ruh sağlığı ve psikiyatri hemşireliği klinik simülasyonunda standardize hasta kullanımı}

Simülasyonda standardize hastanın kullanımı, simülasyona dayalı öğrenim yaklaşımlarından biri olup, hemşire eğiticiler arasında sıklıkla sağlığı değerlendirme becerileri ve terapötik iletişimi geliştirmede kullanılmaktadır. Standardize hasta; eğitim, uygulama ya da değerlendirme amaçları için yazılmış senaryolarda bir hasta ya da başka bir bireyin rolünü oynayan eğitilmiş kişidir $(6,10)$.

Standardize hasta kullanılarak yapılan ruh sağlığı ve psikiyatri hemşireliği simülasyonlarında öğrenciler, klinik uygulama sırasında karşılaşacakları ve/veya karşılaşma olanağına sahip olamayacakları psikiyatrik belirtileri taklit eden standardize hastalarla çalışarak deneyim kazanırlar $(4,8)$. Ek olarak, standardize hasta tarafından verilen geri bildirimler öğrenciye, klinik becerisinin ve ruhsal bozukluğu olan birey ile kurduğu terapötik iletişimin etkinliğini değerlendirme imkânı sunar $(6,12)$.

Yapılan çalışmalar, standardize hasta kullanılarak yapılan simülasyonların beceri kazandırma ve öğrencilerin stresini azaltmada etkili bir yöntem olduğunu belirtmektedir $(6,11,12,13,14,15,16,17,18)$.

Bu çalışmada; bir vakıf üniversitesinin simülasyon merkezinde Ruh Sağlığı ve Hastalıkları Hemşireliği dersi kapsamında standardize hasta kullanılarak gerçekleştirilen klinik simülasyonun planlanması ve sonuçları paylaşılacaktır.

\section{Simülasyon tasarımı}

Simülasyonun amacı ve öğrenim hedefleri

Simülasyonun amacl; öğrencilerin, ruhsal bozukluğu olan bireyin ruhsal durum değerlendirmesini yapmasıdır.

Simülasyonun öğrenim hedefleri ise, öğrencinin; ruhsal bozukluğu olan birey ile terapötik ilişki kurabilmesi, terapötik iletişim tekniklerini kullanabilmesi ve ruhsal durumunu değerlendirebilmesidir.

\section{Simülasyon senaryolarının oluşturulması}

Klinik simülasyon öncesi, senaryo içerikleri Medikal Simülasyon Eğitici Eğitimi almış Ruh Sağlığı ve Hastalıkları Hemşireliği dersinin klinik uygulamasından sorumlu öğretim üyesi, öğretim elemanı ve simülasyon merkezi 
hemşirelik eğitmeni tarafından hazırlandı. Katılımcıların klinik uygulama esnasında karşılaşma olanağının en yüksek olduğu ruhsal bozukluklardan olan; şizofreni, majör depresyon ve bipolar bozukluk (manik evre) olmak üzere üç olgu örneğinin klinik durumuna uygun şekilde senaryolar oluşturuldu (Tablo 1,2,3). Provada kullanmak amacıyla; ruhsal durum değerlendirme basamakları göz önüne alınarak, kolaylaştırıcılar tarafından her bir olgu için olası senaryo metinleri oluşturuldu.

\section{Standardize hasta seçimi ve prova süreci}

Her üç senaryo için gereksinim duyulan standardize hastalar, simülasyon merkezinde daha önce birçok eğitimde rol almış olan profesyonel oyunculardan seçildi. Standardize hastalarla senaryo içerikleri ve akışı görüşüldü. Senaryo metni prova öncesi e-posta yoluyla gönderildi ve prova tarihleri belirlendi. Her bir oyuncuyla birer saatlik prova gerçekleştirildi.

Provanın içeriğini; oyuncuya simülasyonun ve öğrenim hedeflerinin aktarılması, senaryo metninin birlikte okunarak düzenlemelerin yapılması, oyuncunun senaryodaki rolünü canlandırması ve değerlendirme oluşturdu.

Provada ilk olarak oyuncuya; simülasyonun yapılacağı alan tanıtıldı. Daha sonra bu alanda ruh sağlığı ve psikiyatri hemşireliğinde klinik simülasyonun önemi, planlanan simülasyonun amacı ve öğrenim hedefleri aktarıldı. İkinci

\section{Tablo 1. Şizofreni senaryosu}

\section{Öğrenim Hedefleri}

1. Öğrenci, şizofreni tanılı yetişkin hastayla terapötik ilişki kurabilir,

2. Öğrenci, şizofreni tanılı yetişkin hastada terapötik iletişim tekniklerini kullanabilir,

3. Öğrenci, şizofreni tanılı yetişkin hastanın ruhsal durumunu değerlendirebilir.

\section{Olgu Sunumu}

Ahmet B.; 23 yaşında, erkek, İzmir'de üniversite son sınıf öğrencisi ve şu anda ailesiyle yaşayan bir gençtir. Yaklaşık 8 ay önce üniversiteyi bıraktığı ve ailesiyle yaşamak üzere İstanbul'a geri döndüğü öğrenildi. Dönüşünden beri odasına kapanan A.B.'nin gittikçe artan çekingenliği ve şüpheciliğinin ardından babasıyla mutfakta yaşadığı sözlü bir tartışma sonrası bıçaklı saldıı girişiminde bulunması sebebiyle ailesi tarafından bir hafta önce acil servise getirildi.

Aile üyelerinden; ebeveynlerine daha önce hiç görmedikleri kadar tuhaf baktı̆ı, onları tanımadığı, onlarla konuşmayı reddettiği, gün boyunca odasından çıkmadığı ve tüm yardımları reddettiği bilgisi alındı. Yapılan değerlendirme sonrasında A.B.'nin şizofreni ön tanısıyla kliniğe yatışı yapıldı.

\section{Planlama}

Çalıştığınız psikiyatri servisinde bir haftadan beri klinikte yatmakta olan A.B. ile bugün siz ilgileniyorsunuz. Kapıdan içeri girdiğinizde; yatağa oturmuş, pencereden dışarı bakıyor.

\section{Hemşirelik Planlaması}

1. Hasta-hemşire iletişimini başlatın.

2. Terapötik iletişim tekniklerini kullanın.

3. Ruhsal durumunu değerlendirin.

4. Uygun şekilde görüşmeyi sonlandııın.

\section{Tablo 2. Majör depresyon senaryosu}

\section{Öğrenim Hedefleri}

1. Öğrenci, majör depresyon tanılı yetişkin hastayla terapötik ilișki kurabilir,

2. Öğrenci, majör depresyon tanılı yetişkin hastada terapötik iletişim tekniklerini kullanabilir,

3. Öğrenci, majör depresyon tanılı yetişkin hastanın ruhsal durumunu değerlendirebilir.

\section{Olgu Sunumu}

Elif S.; 35 yaşında, kadın, ev hanımı, 10 yıllık evliliği olan ve çocuğu olmayan biridir. Yapılan görüşmede, eşini 6 ay önce akut miyokard enfarktüsü nedeniyle kaybettiği öğrenildi. Evde eşinin hiçbir eşyasını atmadığını, hepsinin yerinde durduğunu ifade etti. Eşinin ölümünden kısa bir süre sonra evden günlerce çıkmak istemediğini ve arkadaşlarının davetlerini reddettiğini, sadece her gün mezarlığa gidip eşini ziyaret ettiğini belirtti. Görümcesinin üç gün önce yaptığı ziyaret esnasında E. S.'nin ev içinde hiçbir şey yapmadan oturması, boşluğa gözlerini dikerek bakması, yemek yememesi ve "Daha fazla yaşamak istemiyorum, Hakan olmadan yaşamamın hiçbir anlamı yok." demesi üzerine görümcesinin endişelendiği ve doktora görünmesi konusunda onu ikna ederek hastaneye getirdiği öğrenildi. Yapılan değerlendirme sonrasında E.S.'nin majör depresyon ön tanısıyla kliniğe yatışı yapııdı.

\section{Planlama}

Çalıştığınız psikiyatri servisinde üç gün önce kliniğe yatışı yapılan E. S. ile bugün siz ilgileniyorsunuz. Kapıdan içeri girdiğinizde; yatağa oturmuş, pencereden dışarıya bakıyor.

\footnotetext{
Hemşirelik Planlaması

1. Hasta-hemşire iletişimini başlatın.

2. Terapötik iletişim tekniklerini kullanın.

3. Ruhsal durumunu değerlendirin.

4. Uygun şekilde görüşmeyi sonlandırın.
} 


\section{Tablo 3. Bipolar bozukluk (Manik Evre) senaryosu}

\section{Öğrenim Hedefleri}

1. Öğrenci, bipolar bozukluk tanıılı yetişkin hastayla terapötik ilişki kurabilir,

2. Öğrenci, bipolar bozukluk tanılı yetişkin hastada terapötik iletişim tekniklerini kullanabilir,

3. Öğrenci, bipolar bozukluk tanılı yetişkin hastanın ruhsal belirtilerini değerlendirebilir.

\section{Olgu Sunumu}

Deniz Y.; 28 yaşında, kadın, 10 yıldır evli, 7 ve 10 yaşında iki çocuğu var. Bir firmada mali işler yetkilisi olarak çalışan D. Y., iki hafta önce işyerinde sorumlusu tarafından; müşterilerle ilgisiz konularda çok fazla konuşması, ofis içerisinde yüksek sesle şarkı söylemesi ve diğer çalışanlara sinirlenmesi nedeniyle uyarı aldığını ifade etti. Bu dönem içerisinde günlük yaşamında ise sürekli alışveriş yapıp hediyeler alması, uyuyamaması, kendini "bomba" gibi hissetmesi ve engellendiği durumlarda saldırganlaşması üzerine eşi tarafından acil servise getirildi. Yapılan değerlendirme sonrası D.Y.'nin bipolar bozukluk (manik evre) ön tanısıyla kliniğe yatışı yapıldı.

\section{Planlama}

Çalışıı̆ıınız psikiyatri servisinde dünden beri klinikte yatmakta olan D.Y. ile bugün siz ilgileniyorsunuz. Kapıdan içeri girdiğinizde; odada dolaşarak şarkı söylüyor.

\section{Hemşirelik Planlaması}

1. Hasta-hemșire iletișimini bașlatın.

2. Terapötik iletişim tekniklerini kullanın.

3. Ruhsal durumunu değerlendirin.

4. Uygun şekilde görüşmeyi sonlandırın.

aşamada, oyuncuyla senaryo metni gözden geçirildi ve senaryo metninde yer almayan, öğrencilerden gelebilecek farklı soru örnekleri ve oyuncudan beklenen yanıtlar çalışıldı. Son aşamada ise; eğitmenin de dâhil olduğu provalar gerçekleştirildi ve senaryo metninin son hali oluşturuldu.

\section{Katılımcı profili}

Klinik simülasyonun katılımcı profilini, daha önce Ruh Sağlığı ve Hastalıkları Hemşireliği ile ilgili simülasyon uygulamasına katılmamış olan ve kayıtlı oldukları dönemde Ruh Sağlığı ve Hastalıkları Hemşireliği dersini alan 50 hemşirelik öğrencisi oluşturdu.

\section{Simülasyona hazırlık}

Klinik simülasyon; akademik yılın üçüncü haftasında klinik uygulama gününe planlandı. Simülasyon öncesi ilk iki hafta sadece 25 saatlik teorik eğitim yapıldı. Katılımcılara müfredatta yer alan; ruhsal bozukluğu olan birey ile terapötik iletişim, Ruh Sağlığı ve Psikiyatri Hemşireliği süreci, şizofreni ve hemşirelik yaklaşımı, bipolar bozukluklar ve hemşirelik yaklaşımı, depresyon ve hemşirelik yaklaşımı konuları dersin öğretim üyesi tarafından anlatıldı. Son teorik dersin ardından katılımcılara klinik simülasyona hazırlanmaları için senaryolar ve öğrenim hedefleri e-posta yoluyla iletildi.

Klinik simülasyonda öğrenciler; rastgele 16-17 kişiden oluşan üç gruba ayrıldı. Şizofreni, majör depresyon ve bipolar bozukluk (manik evre) olmak üzere toplam üç ayrı istasyon hazırlandı. Senaryolar için belirlenen üç istasyonda, psikiyatri yatan hasta servisi ortamı oluşturuldu. Standardize hastalara bulundukları istasyonlara uygun olarak kıyafet ve mulaj çalışması yapıldı. Senaryo araları standardize hastanın hazırlanması için iki dakika olarak belirlendi.
Ruhsal durum değerlendirme basamakları doğrultusunda katılımcıların simülasyon esnasında kullanmaları için "Ruhsal Durum Değerlendirme Formu" oluşturuldu. Her simülasyon uygulamasında katılımcının değerlendirilmesi için ilgili form, 0 - Başarısız, 1 - Geliştirmesi Gerekli, 2 - Başarılı parametrelerinin yer aldığı "Katılımcı Değerlendirme Formu"na dönüştürülerek kolaylaştırıcılar tarafından kullanıldı.

\section{Ön bilgilendirme (Prebriefing)}

Gruplara daha önceden belirlenmiş istasyon alanları, istasyondan sorumlu kolaylaştırıcı tarafından tanıtıldı ve öğrenim hedefleri aktarıldı. Simülasyonda yer alan olgular ve süre ile ilgili bilgi verildi. Simülasyon sırasında öğrenci tarafından olgu görüşmesinde kullanılacak olan "Ruhsal Durum Değerlendirme Formu" her öğrenciye istasyon kolaylaştırıcısı tarafından anlatıldı. Kayıt altına alınarak gerçekleştirilecek simülasyon uygulamaları için her bir öğrenciden yazılı onam alındı.

\section{Simülasyon süreci}

Her grupta onar dakikalık simülasyonların video kayıtları kolaylaştırıcı tarafından kayıt altına alındı. Simülasyon uygulaması sırasında her istasyon için hazırlanmış 'Katııımc Değerlendirme Formu" kolaylaştırııılar tarafından katılımcıları değerlendirmede kullanıldı.

\section{Çözümleme (Debriefing)}

Simülasyon uygulamaları sonrası çözümleme, aynı anda her istasyonun kendi kolaylaştırıcısı eşliğinde PEARLS (Promoting Excellence and Reflective Learning in Simulation) çözümleme çerçevesi kullanılarak gerçekleștirildi. PEARLS; katıımcının kendi kendini değerlendirmesi, 
Tablo 4. Klinik simülasyon memnuniyet anketi katılımcı görüşleri

\begin{tabular}{|c|c|c|c|}
\hline Maddeler & KatıImıyorum & Kararsızım & Katılıyorum \\
\hline $\begin{array}{l}\text { Standardize hastayla görüşme } \\
\text { yönteminin kullanılması etkili ve } \\
\text { yararlı oldu. }\end{array}$ & $n=0$ & $\begin{array}{c}n=2 \\
\% 4\end{array}$ & $\begin{array}{c}n=48 \\
\% 96\end{array}$ \\
\hline $\begin{array}{l}\text { Standardize hastaya dayalı } \\
\text { öğretim şekli benim öğrenme } \\
\text { yöntemim ile uyumluydu. }\end{array}$ & $n=0$ & $\begin{array}{c}n=10 \\
\% 20\end{array}$ & $\begin{array}{c}n=40 \\
\% 80\end{array}$ \\
\hline $\begin{array}{l}\text { Standardize hasta ile görüşme } \\
\text { yapmak klinik uygulama öncesi } \\
\text { özgüvenimi arttırdı. }\end{array}$ & $n=0$ & $\begin{array}{l}n=5 \\
\% 10\end{array}$ & $\begin{array}{c}\mathrm{n}=45 \\
\% 90\end{array}$ \\
\hline $\begin{array}{l}\text { Standardize hasta ile görüşme } \\
\text { yapmak klinik uygulama öncesi } \\
\text { anksiyetemi azalttı. }\end{array}$ & $n=0$ & $\begin{array}{l}n=5 \\
\% 10\end{array}$ & $\begin{array}{c}n=45 \\
\% 90\end{array}$ \\
\hline $\begin{array}{l}\text { Standardize hasta ile } \\
\text { görüşmemin, psikiyatri } \\
\text { hemşireliği klinik uygulamasında } \\
\text { bana yardımcı olacağına eminim. }\end{array}$ & $n=0$ & $\begin{array}{c}n=2 \\
\% 4\end{array}$ & $\begin{array}{c}n=48 \\
\% 96\end{array}$ \\
\hline $\begin{array}{l}\text { Terapötik iletişim becerilerini } \\
\text { standardize hasta senaryosu } \\
\text { esnasında etkili kullanabildiğimi } \\
\text { düşünüyorum. }\end{array}$ & $\begin{array}{c}n=3 \\
\% 6\end{array}$ & $\begin{array}{c}n=16 \\
\% 32\end{array}$ & $\begin{array}{c}n=31 \\
\% 62\end{array}$ \\
\hline $\begin{array}{l}\text { Standardize hasta } \\
\text { senaryosunun kullanımı ruhsal } \\
\text { bozukluk belirtilerini tanımama } \\
\text { yardımcı oldu. }\end{array}$ & $\mathrm{n}=0$ & $\begin{array}{c}n=2 \\
\% 4\end{array}$ & $\begin{array}{c}n=48 \\
\% 96\end{array}$ \\
\hline $\begin{array}{l}\text { Standardize hasta senaryosu } \\
\text { görüşme esnasında uygun } \\
\text { soruları yöneltmeme } \\
\text { olanak sağladı. }\end{array}$ & $\begin{array}{c}n=3 \\
\% 6\end{array}$ & $\begin{array}{c}n=14 \\
\% 28\end{array}$ & $\begin{array}{c}n=33 \\
\% 66\end{array}$ \\
\hline
\end{tabular}

odak tartışmayı kolaylaştırma ve yol gösterici geri bildirim ve / veya öğretme yoluyla bilgi sunma gibi üç yaygın eğitim stratejisini bütünleştirmektedir. Bu çerçeve; reaksiyon, tanımlama, analiz ve özetleme aşamalarından oluşmaktadır. Çerçevenin kullanımı; klinik karar verme, teknik becerilerin geliştirilmesi, ekip çalışması eğitimi ve meslekler arası işbirliği gibi çeşitli hedefler ile planlanan simülasyonların çözümlemeleri için uyarlanabilir bir yapı sağlamaktadır (19).

Çözümleme esnasında süre kısıtlaması nedeniyle her grupta beş katııımcının video kaydı seyrettirildi. Çözümleme; video kayıtlarının seyredilmesi, standardize hasta ve katılımc bildirimlerinin alınmasıyla her bir grup için iki saatte tamamlandı.

Çözümleme aşamasının sonunda katılımcılara kolaylaştırıcılar tarafından hazırlanan"Klinik Simülasyon Memnuniyet Anketi" uygulandı. Tablo 4'te katılımcıların görüşleri incelendiğinde; \%96'sının standardize hastayla görüşme yapmayı etkili ve yararlı bulduğu, \%80'inde standardize hastanın katılımcının öğrenme yöntemiyle uyumlu olduğu, \%90'ının klinik uygulama öncesi özgüveninin arttığı ve anksiyetesinin azaldığı, \%96'sının simülasyonun klinik uygulamada yardımcı olacağını düşündüğü, $\% 62$ 'sinin terapötik iletişim becerilerini etkili kullandığı, \%96'sının ruhsal bozukluk belirtilerini tanımasını sağladığını ve $\% 66$ 'sının görüşme esnasında uygun sorular sorduğunu düşündüğü belirlendi.

\section{Tartışma}

Öğrencilerin, ruhsal bozukluğu olan bireyin ruhsal durum değerlendirmesini yapabilmesi amacıyla gerçekleştirilen bu klinik simülasyonda; öğrencilerin bildirimleri sonucun$\mathrm{da}$, standardize hasta rolünde profesyonel oyuncunun yer almasının yüksek gerçeklik sağlamada etkili olduğu gözlemlendi.

D. - Kendimi stajdaymışım sandım. Depresif biriyle nasıl konuşmam gerektiğini, dinlemenin ve iletişim kurmanın ne kadar önemli olduğunu anladım.

Y. - Gerçek bir hasta gibi iletişime geçmiş olmam hastaneye gitmeden hastalara nasıl davranmam gerektiğini ve soru sorarken nelere dikkat etmem gerektiğini bana öğretti. Deneyim kazanmak güzeldi.

Simülasyonda standardize hasta rolünde profesyonel oyuncuların var olmasının, psikiyatri hastaları gibi belirli gruplarda yaygın görülen durumları ve sorunları fark etmede; öğrencilerin iletişim becerilerini, öz yeterliğini, öğrenme motivasyonunu arttırmada ve teorik bilginin uygulama becerisine aktarılmasında faydalı olduğu belirtilmektedir $(16,20)$.

Standardize hasta kullanılarak yapılan simülasyonlarda, profesyonel oyuncunun öğrenciye en iyi simülasyonu, akademik personelin ise, en olumlu öğrenme deneyimini sağladığı ifade edilmektedir (21). Standardize hasta kullanılarak yapılan bu simülasyonda öğrencilerin bildirimlerine bakıldığında; öğrenim hedeflerine ulaşmada simülasyonun etkili olduğu saptandı.

K. - Hastada mani belirtileri vardı. Iletişim yönünden iyiydim ama bazen hastayı konuya odaklamada zorlandım.

M. - Depresif hastayla görüşürken terapötik iletişim tekniklerini kullanabildim ama kendimi geliştirmem gerektiğini düşünüyorum.

R. - Hastanın halüsinasyonu olduğunu fark ettiğimde önce ne diyeceğimi bilemedim. Sonra onu gerçeğe getirmeye çalışım. 
Choi (2013) tarafından 16 öğrenci ile yapılan psikiyatri hemşireliği simülasyonunda; standardize hasta rolü için seçilen üç psikiyatri hemşiresiyle 10 saatlik bir prova planlandığı belirtilmektedir (13). Bu simülasyonda ise, standardize hasta rolü için seçilen profesyonel oyuncuların her biriyle bir saatlik prova yapılması, sağlık çalışanı yerine profesyonel oyuncularla yapılan standardize hasta provalarının daha kısa sürede tamamlanması ve zaman tasarrufu sağlaması yönünden avantajlı bir durum olduğu söylenebilir.

Bu simülasyonda; profesyonel oyuncularla yapılan provalarda önceden oluşturulan ve prova öncesi oyuncularla paylaşılan senaryo metinlerinin kullanımının, standardize hastaların rollerini etkin şekilde oynamasında faydalı olduğu düşünülmektedir. Choi (2013) tarafından yapılan çalışmada da açıklayıcı notlar ya da basit komutların yer aldığı formatlar yerine senaryo metinlerinin oluşturulmasının, rol canlandırma uygulamalarının standardizasyonunda önemli olduğu belirtilmektedir (13).

Gerçekleştirilen simülasyonda; senaryo içeriklerinin öğrencilerin klinik uygulamada karşılaşma olanağının en yüksek olduğu üç farklı ruhsal bozukluktan seçilmesinin, öğrencilerin yaşadıkları farklı simülasyon deneyimlerini klinik uygulamada birbirlerine aktararak klinik becerilerini arttırmalarına katkı sağlayacağı düşünülmektedir.

\section{Kaynaklar}

1. Özbaş D, Buzlu S. Geçmişten Günümüze Psikiyatri Hemşireliği. IÜFN Hem Derg 2011;19:187-193. Erişim: https://dergipark.org.tr/ download/article-file/95082

2. Ewashen C, Lane A. Pedagogy, Power and Practice Ethics: Clinical Teaching in Psychiatric/Mental Health Settings. Nurs Inq 2007;14:255-62. [CrossRef]

3. Alzayyat A, Almaraira OA, Al-helih YM. Stress and Coping Among Nursing Students During Their Practical Education in Psychiatric Settings: A Literature Review. Glo Adv Res J Med Med Sci 2015;4:240-7.

4. Kameg K, Howard VM, Clochesy J, Mitchell A, Suresky JM. The Impact of High Fidelity Human Simulation on Self-Efficacy of Communication Skills. Issues Ment Health Nurs 2010;31:315-23. [CrossRef]

5. Szpak JL, Kameg KM. Simulation Decreases Nursing Student Anxiety Prior to Communication With Mentally III Patients. Clin Simul Nurs 2013;9:e13-9. [CrossRef]

6. Robinson-Smith G, Bradley PK, Meakim C. Evaluating The Use of Standardized Patients Undergraduate Psychiatric Nursing Experiences. Clin Simul Nurs 2009;5:e203-11. [CrossRef]

7. Lehr ST, Kaplan B. A Mental Health Simulation Experience For Baccalaureate Student Nurses. Clin Simul Nurs 2013;9:e425-31. [CrossRef]

8. Brown JF. Applications of Simulation technology in Psychiatric Mental Health Nursing Education. J Psychiatr Ment Health Nurs 2008;15:638-44. [CrossRef]

\section{Sinırlılıklar}

- Simülasyonda planlanan üç ayrı senaryoya öğrencilerin rastgele ayrıldığı gruplara göre girmesi,

- Çözümleme esnasında süre kısıtlaması nedeniyle tüm simülasyon uygulamalarının videoları yerine rastgele seçilen 5 videonun öğrencilere izlettirilmesi ve değerlendirilmesi simülasyonun sınırlılığıdır.

\section{Sonuç}

Standardize hasta kullanılarak yapılan klinik simülasyonun, öğrencilerin klinik uygulama öncesi anksiyetelerini azaltmada, özgüvenlerini geliştirmede ve öğrenim hedeflerine ulaşmada etkili olduğu görüldü. Simülasyona dayalı eğitimin öğrencilerin iletişim becerilerini, ekip çalışmasını ve kriz durumlarını yönetme yeteneğini geliştirmede kullanılabilecek bir yöntem olduğu göz önüne alındığında; ruh sağlığı ve psikiyatri hemşireliği eğitiminde simülasyonun müfredata entegre edilerek basit ve karmaşık senaryoların yer aldığı klinik simülasyonların planlanması önerilmektedir.

\section{Teşekkür}

Çalışmaya bilimsel danışmanlık yaparak katkı veren Prof. Dr. Sema Kuğuoğlu'na teşekkürlerimizi sunarız.

9. Dearing KS, Steadman S. Enhancing Intellectual Empathy: The Lived Experience of Voice Simulation. Persp Psychiatr Care 2009;45:17382. [CrossRef]

10. Meakim C, Boese T, Decker S, Franklin AE, Gloe D, Lioce $L$, et al. Standarts of Best Practice: Simulation Standart I. Terminology. Clin Simul Nurs 2013;9:S3-11. [CrossRef]

11. Becker KL, Rose LE, Berg JB, Park H, Shatzer JH. The Teaching Effectiveness of Standardized Patients. J Nurs Educ 2006;45:103-11.

12. Doolen J, Giddings M, Johnson M, Guizado de Nathan G, Badia LO. An Evaluation of Mental Health Simulation With Standardized Patients. Int J Nurs Educ Scholar 2014;11:1-8. [CrossRef]

13. Choi Y. Standardized Patients For Korean Psychiatric Nursing Student Simulations. Clin Simul Nurs 2013;9:e385-92. [CrossRef]

14. Mackey S, Tan KK, Ignacio J, Palham S, Dawood RBM, Liaw SY. The Learning Experiences of Senior Student Nurses Who Take on The Role of Standardised Patient: A Focus Group Study. Nurs Educ Pract 2014;14:692-7. [CrossRef]

15. Webster D. Using Standardized Patients to Teach Therapeutic Communication in Psychiatric Nursing. Clin Simul Nurs 2014;10:e816. [CrossRef]

16. Oh PJ, Jeon KD, Koh MS. The Effects of Simulation-Based Learning Using Standardized Patients in Nursing Students: A Meta Analysis. Nurs Educ Today 2015;35:e6-15. [CrossRef]

17. Piette A, Muchirahondo F, Mangezi W, Iversen A, Cowan F, Dube M, et al. Simulation-Based Learning in Psychiatry for Undergraduates at The University of Zimbabwe Medical School. BMC Med Educ 2015;15:1-8. [CrossRef] 
18. Brown AM. Simulation in Undergraduate Mental Health Nursing Education: A Literature Review. Clin Simul Nurs 2015;11:445-9. [CrossRef]

19. Eppich W, Cheng A. Promoting Excellence and Reflective Learning in Simulation (PEARLS): Development and Rationale for a Blended Approach to Health Care Simulation Debriefing. Simul Healthcare 2015;10:106-15. [CrossRef]
20. Keltner NL, Grant JS, McLeron D. Use of Actors As Standardized Psychiatric Patients: Facilitating Success in Simulation Experiences. J Psychosoc Nurs Ment Health Serv 2011;49:34-40. [CrossRef]

21. Mavis B, Turner J, Lovell K, Wagner D. Faculty, Students, and Actors As Standardized Patients: Expanding Opportunities For Performance Assesment. Teach Learn Med 2006;18:130-6. [CrossRef] 